\title{
SECURING PUBLIC CO-OPERATION IN FOREST PROTECTION
}

\author{
H. W. Crosbie, District Forester, Tweed, Ont.
}

$\mathrm{T}$

HE subject upon which I had been requested to prepare a paper for this meeting is "Securing public co-operation in forest protection."

At our present stage of forest management the phase of co-operation in connection with forest protection is of greatest importance and coroperation obtained in this specialized phase of forest management will serve as a foundation for all other phases of forestry which will in time become of greater importance. In treating a subject covering as wide a scope as this, the different divisions must necessarily be covered in rather a broad way and no detailed analysis of various methods involved has been attempted.

"Prevent Forest Fires-It Pays" is the slogan of nearly all forest protection services in United States and Canada. Thousands of posters have been placed in or near the woods giving warning against forest fires. Expensive signs have been erected, much literature distributed and many articles written for and published by the newspapers and magazines. Conservation associations and clubs have been formed. The radio has been used as a medium. Costly advertising has been carried by the press. Laws have been enacted. Prosecutions for offence against law have been carried out and penalties imposed. Motion pictures depicting the effect of uncontrolled forest fires have been shown to millions. Stirring addresses have been delivered from the public platform. Expensive and highly efficient forest services have been devised and much money spent in equipping these services. In forest protection much time has been devoted by organization staffs in presenting this idea to the people. Investigations as to cause and effect of forest fires have been carried out and results made known to the public. All these methods have been used in calling public attention to the same thing that "THE PREVENTION OF FOREST FIRES PAYS." The questions naturally arise- "Are our methods of presenting this idea to the public proper and effective? Are we neglecting to use more effective methods? Are we getting results that are commensurate with the time and money spent?"

It is realized that the only logical way we have of producing change in the human mind is by education. EDUCATION of the individual to the importance of forest fire prevention is an enormous task that cannot be accomplished by any one method nor in any given time. People are very often too indifferent to the safety of the property of others, too unknowing of their own interests in the perpetuation of a great natural resource, too unappreciative of the value of crown owned property, too unmindful of their own future comfort. The average person is so different from his fellows that 
all cannot be reached and interested by the same means. Education of a very large percentage of our people who live in or use our forests for work or recreation is our solution. "I must be more careful with fire in or near the forest than I am in my own home" must be the thought to be constantly hammered in.

While it is true that it is the duty of a government to take care of its own interests both as a timber land owner and because of the benefits to society, it must be understood that the government is made up of individuals who live within its borders. The results of forest fires touch the life of every individual within the bounds of that government. Therefore it is the duty of every citizen to do his or her share by co-operating with the government's agents, the forest service, not only in the suppression of forest fires but also in their prevention. Without this whole-hearted co-operation the task of saving our forest from fire is going to be very difficult and costly.

Approximately ninety percent of the forest fires in Canada are the result of human action. The remainder are caused by lightning or a very few by spontaneous combustion. Now to prevent these large numbers of preventable fires through the medium of cooperation between the woodsusing public and the forest protection organizations and other conservation organizations is our task.

Now let us examine the various methods we are using of attempting to secure this much desired and necessary co-operation.

The press has been of immeasurable value and has had a tremendous effect in creating in the public mind an awareness of forest value and the necessity of care with our forests. These facts are as yet not fully appreciated, but through continued work on the part of the press this awareness will become more general and the public will demand greater expenditures of the nation's money for the conservation of our forests and will at a personal sacrifice assist the various organizations in this work of forest protection. Press activities may be divided into publicity of articles prepared, reporting of addresses, editorials written and published, paid advertising and reporting of the activities of the various forest protection services. We must realize and appreciate the excellent publicity material that has been produced and the many handicaps that have been overcome before it was possible to produce this material. We may be justly proud of progress along this line, but we should not be satisfied to continue without progress towards better and greater publicity for the future. We should appreciate that we live in an age of speed and rapid changes and our future publicity should keep pace with the times. Most of our publicity has been in the expression of the scientist, economist, aesthete, or humorist. Rarely has our publicity been varied to include the ingredients of all. In other words all forestry publicity should be built up to a high standard of quality. Meager or stilted publicity is not in keep- 
ing with the important place that the forests of Canada occupy in our economic life.

Unfortunately much valuable publicity is lost through the indifference of forest services to make their activities known to the press. There appears to be an opportunity afforded for the establishment of better relations between the press and forest services. Valuable work in this direction has been performed by those in the forest services responsible but it is felt that it is inadequate and greater efforts should be made to increase the amount of publicity. That columns of newspapers and pages of magazines should be devoted to this subject proves its importance. It is largely through these means that the greater fundamental issues are brought before a people. These articles provide the slogans and material for carrying forward the work to be done. Organizations that are doing forest protection work will find a ready response from most of the editors of the country.

Paid advertising has been much used to acquaint the public with the necessity of care of fre in the forest. Much of this has been presented in the form of cold, hard-boiled facts. It is realized that there is no one best method of advertising. The selection of our method of presentation must de\& pend upon where we want our message to go and we should select that to medium which will present the message with maximum clarity, interest and $\dot{\sigma}$ speed. We can learn much from commercial advertising. One has only to $\dot{r}$ read the better class of advertisements to realize how skilfully and subtly the established laws of psychology are used in the appeal for the sale of a parto ticular product. Graphic charts and curves and "reasons why" have their Wace as specialized material for special occasions, but the publicity material That is intended for the public en masse must be prepared within the range of the public's mental grasp.

[न] I have not included the work of the Canadian Forestry Association in the E g giscussion of press. It is felt that it is apart, a specialized agency of publicity Employing not only the press but other valuable instruments such as the Tlatform and motion pictures. As an administrative officer of a forest pro. tection service who comes intimately in touch with the effects of the work of the Canadian Forestry Association, I cannot speak too highly of it. In my $\AA$ work I have come in contact with hundreds of people whose interest in forest o conservation has been aroused by the Canadian Forestry Association through its publication "Forest and Outdoors." The stories published in this magazine have a strong human appeal, stimulating interest, love of forests, and an ap$>$ preciation of this economic value. I realize that the Forest and Outdoors does not appeal strongly to the average forester. It is elementary as it is intended to reach the people to whom the contents are not elementary and is a strong I factor in arousing a public interest in forests. The magazine has done much, $F$ but in my opinion their travelling lecturers and motion picture tours have done 
more. They have reached and appealed to that class of people who are beyond the influence of the press and this class of people in many forested districts forms a large percentage of the inhabitants. There is established by this method a direct appeal to those in the position to co-operate with the local forest service. In understandable language co-operation is requested and through the agency of the motion picture the mind through the eye receives an appeal to reason for cooperation. The work of the Canadian Forestry Association in the schools is showing and will in the future show immeasureable returns. It is my earnest hope that the Association will continue to enlarge its activities and that those vitally interested in forest conservation will co-operate with this Association to the fullest extent.

In addition to the Canadian Forestry Association a few local societies, clubs and associations have been founded with the purpose of stimulating interest in Forest Conservation. Several of these clubs have performed excellent work, but I do not think that this means for the purpose has been suf, ficiently stimulated. Greater efforts in this direction should be made. Many services in the United States have successfully established such organizations, and I believe that many are doing valuable work.

The radio has been very effectively employed in requesting greater care with fire in the woods. What has been said about press publicity is true of radio publicity. While splendid addresses have been given to the public through this medium, many of them have been cold and uninteresting. The appeal, to be effective, must carry a human appeal to interest the masses. We can learn much from commercial advertisers who use the radio most effectively. A five minute story with fifty-five minutes devoted to the creation of atmosphere will be more effective and appeal to a greater number than a much longer period devoted to the making of statements of facts. Radio has, to a limited extent, been used to issue warnings in times of high fire hazard. This service could be enlarged with good effect.

Public addresses have done much to inform the public of the necessity of conservation of our forests. Forest officers themselves can do immeasurable good by addressing audiences in or near forest territory, placing before them the situation as it is directly applicable to the audience. A direct appeal of this nature is of greater value than one of general public appeal. An excellent opportunity is offered by this type of address to bring the problems of a forest service directly before an interested audience.

Posters and signs play an important part of direct publicity, particularly in the forest. These have value, particularly for their appeal at the proper time and place. Much improvement can be made in this method of advising the forest users that FOREST FIRE PREVENTION PAYS. We have had the tendency to be too polite in most of our sign appeals. The appeal should be short but impressive, giving food for thought. They should be attractive-a 
thing of beauty which does not mar the surrounding landscape. Judgment should be used in the placing of proper signs in the proper place. Last season I noticed a sign drawing the attention of motorists to the necessity of care with cigarettes while travelling, placed forty miles from the nearest travelled road. Perhaps the local ranger has advanced ideas, because I think this sign was read and commented upon more than those we considered applicable.

Much literature, particularly in the form of government pamphlets, has been distributed to the public. These pamphlets are excellent, but unfortunately very few reach the people to whom they would do the greatest good.

I will but briefly mention the value of legislation to forest services. Gov. ernment is founded on law, which may be defined as the rules of conduct adopted for the discipline of the whole people. Forest fire laws have been enacted to protect the rights and privileges of the people in forest regions and attempt to insure an adequate supply of timber for the future. Forest protection will be effected principally through co-operation and not through coercion. The administration policy must be a fair and impartial enforcement of the laws; the attitude should not be officious or overbearing, but simply administered in the best interests of the state. Forest protection services have no quarrel with persons who wish to use their land for lawful and useful purposes. For instance, the burning of new land is not a forest fire, but great care must be exercised that it does not result in one. Laws restricting the use of fires are essential. Incendiary forest fires unfortunately occur. These result from deliberate intentional and malicious setting of fire for the sake of burning the woods from some reason or other. Education will reach some of the individuals who cause incendiary fires but mostly they are "old timers" whose ideas we hope will die with them. The best methods I have found to prevent incendiary forest fires is to offer reward for information leading to arrest and conviction and to display posters making the offer known, to catch the incendiary and make an example of him, to arouse public resentment against incendiarism. The display of posters making the reward known has considerable psychological effect and while we have not yet paid the reward offered nor has it been claimed, the value has been very great. When incendiarism is discovered the cause must, if possible, be determined. It may be found that certain restricted use of the forest has found disfavor with the people, unemployment may prevail, or many other causes. In other words, where certain conditions produce an unfavorable attitude in the mind of the incendiary it is well to remove or alter the condition if possible.

Now let me discuss, which, to me, is the most effective and practical method of securing public co-operation from the standpoint of a field administrative officer, that is, through the actions of the personnel of the Forest Protection Services. In the selection of staff for employment in the services for permanent, fire period, or other work, it should be our policy to select. 
the very best help obtainable, giving due regard to experience and other like qualifications. Candidates must be able bodied, capable of enduring hardships and performing severe labor under trying conditions. Pleasing personality, sobriety, industry, good judgment, faithfulness and effectiveness are required of all employees. We are different from most employers in that we do not have direct control over our employees and to a considerable extent we rely on individual initiative, resourcefulness and good judgment of each employee to achieve the highest efficiency.

It is realized that men possessing the listed qualifications are few but many of these qualities lay latent in many men and if we are to have men on our staff possessing these qualifications it will be necessary for us to develop them. An effort towards this development is being made in my forest district by the following methods:-

1. By manuals of instructions.

2. By circulars of instructions.

3. By personal contact.

4. By field inspection.

5. By proper delegation of responsibility.

6. By field instruction classes.

7. By dissemination of information relative to field work.

8. By exchange of duties of personnel.

In the manual of instructions issued the authority, function and responsibility of each member of the staff is definitely outlined so that each person to whom authority is delegated will understand his responsibilities and as sume full responsibility for the exercise of that authority.

Supplementary manual of general instructions, circulars of instructions are issued stating more definitely the functions of individual members of the staff.

The administration officers of the inspectorate spend as much time as is possible in the field, establishing through personal contact and field inspection a close relationship with the field men, personally directing and instructing them in their work.

When rangers are grouped together for improvement work or on other occasions when they can be grouped without interfering seriously with their work, instruction classes are held at which the District Forester, his assistant, or his chief rangers give demonstrations in the use of equipment and lectures on fire protection work. This system has been found to be of great value in better acquainting the staff with their work.

An effort is being made to further develop the ranging staff by the dissemination of literature relative to their work. Copies of articles which appear in technical journals, newspapers, etc., which would be of value, are 
forwarded to the staff. Books and manuals of instructions to other services are circulated.

Rangers are transferred from one position to another that they may become familiar with the duties of other memebers of the service.

It is hoped that in the not too far distant future that we will be able to establish ranger schools in which competent instruction will be given to members of our staff and those intending to become members. Standards of qualifications for entrance will be established and in this way we hope to eliminate the hazard of placing untrained men directly into positions of responsibility and trust. Schools and field training should inculcate into the minds of the personnel "That they are public servants engaged in work which is of vital importance and which offers unusual opportunities for disinterested service. That their work is fire prevention as well as suppression and that fires must be preevnted by the will of the people. They must carry on at all times a strong anti-fire campaign with all persons with whom they come in contact."

Following are suggested methods of obtaining co-operation from the public by forest service staffs:-

Have field staff visit all people resident on their patrols. Have them ex. plain fire laws and the necessity for their observance and make an appeal to reason for co-operation; explain difficulties and value of assistance; discuss burning of slash problems with them; make suggestions as to time and means of burning it; solicit each resident for assistance to be rendered in time of fires; have him fully understand his responsibility; definitely outline what responsibility he may assume; appoint honorary fire rangers or wardens with limited authority, this appointment to be controlled by letter of appointment from the head of the administration unit to which the service employee belongs.

Field rangers should be encouraged to visit all schools in their district, give classes instruction in the care of fire and request that the pupils co-operate by requesting others to be careful. A form of address to classes with outline of subject has been found to be of value to rangers.

Rangers should visit saw-mills, logging operations, road construction work, make suggestions to the operators of method of burning slash to comply with regulations. If possible the ranger should be advised in advance of proposed operations so that he may have the opportunity of discussing plans for hazard removal work with the operator to the advantage of the operator. Rangers should be tolerant to the attitude of those upon whom he must impose regulations, seeking to show by reason the necessity of imposing regulations.

Rangers should spread the gospel of fire protection so that everyone comes to know that forest fire prevention work has come to stay, that forest fires 
are not personal affairs, but that they damage everyone and that they will appreciate co-operation.

Forest service staffs must be impressed with the fact that the best publicity is to show something well done-a fire efficiently fought and extinguished, a properly built and neatly kept ranger station, a good lookout tower scientifically used, a telephone line well constructed and maintained and equipment well cared for. This type of propaganda is exerting and will continue to exert a strong influence on the public mind.

All the mentioned methods of securing public co-operation and many others will do much to gain public co-operation and form public opinion as to the value of a service and it is upon this public opinion that progress in forestry will be made. We live under a government of political parties. The legislator has been put in his pasition by the votes of the people of his constituency. $\mathrm{He}$ is, therefore, anxious to please his voters. He can do so only when he gets an expression of opinion from them.

A final statement--"Co-operation in forestry affairs is not an automatic force that because we set it in motion will run forever in a fixed orbit like a planet in space. It must be boosted, kept in motion, developed, enlarged and improved."

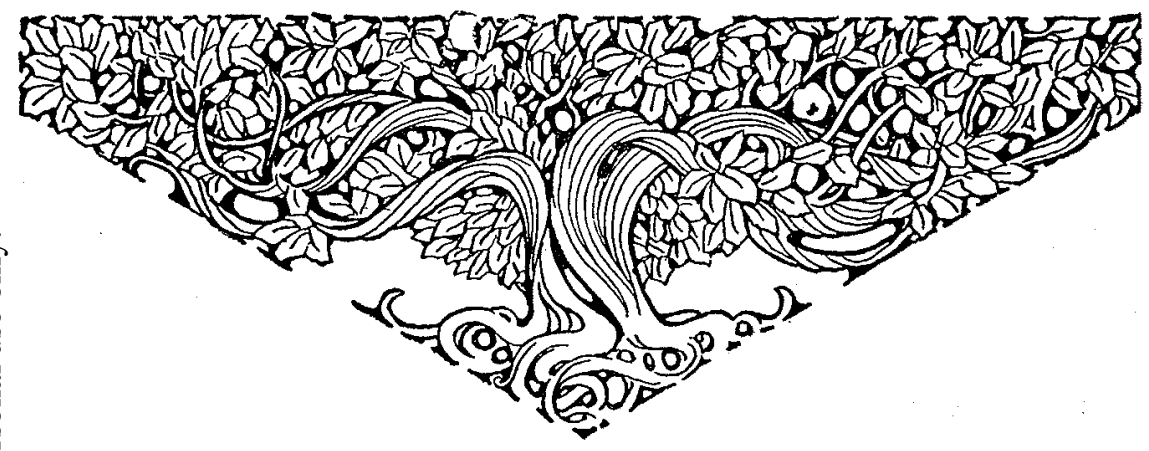

